\title{
Dealing with a family member who has a mental illness was a long term, frustrating, and confusing process before acceptance occurred
}

Karp DA, Tanarugsachock V.Mental illness, caregiving, and emotion management. Qual Health Res 2000 Jan;10:6-25.

\author{
QUESTION: How do parents, spouses, siblings, and children manage their emotions \\ over time when dealing with a family member who has unipolar depression, manic \\ depression, or schizophrenia?
}

Design

Analysis of data from 50 interviews, which were done as part of a larger ethnographic study.

\section{Setting}

Belmont, Massachusetts, USA.

\section{Participants}

50 participants ( $70 \%$ women, $96 \%$ white) were identified from a support group, newspaper advertisements, and recommendations from participants. 18 were parents, 13 were spouses, 10 were children, and 9 were siblings. Occupations were professional $(26 \%)$, white collar $(22 \%)$, clerical (16\%), blue collar $(8 \%)$, student $(12 \%)$, and unemployed $(16 \%)$.

\section{Methods}

Interviews were 2-3 hours long and were audiotaped and transcribed. Data on emotions that accompanied duty, obligation, and responsibility were collated and analysed to develop themes related to living with a family member who has a mental illness.

\section{Main findings}

4 stages in the evolution of the caregiving experience influenced emotions: before a diagnosis, getting a diagnosis, recognising the permanence of the mental illness, and finally, acceptance. Before a diagnosis, caregivers recognised that something had gone wrong with the family member and experienced feelings of uncertainty about the diagnosis and its causes, the potential duration of the illness, as well as anxiety, fear, and confusion. Once a medical diagnosis was made, the "healthy" family members felt that they were obliged to treat the member with mental illness with the same love, understanding, sympathy, and compassion they would have for any family member who was acutely ill. This period often involved learning about the illness. The caregiving role was often embraced fully, enthusiastically, and optimistically.

Caregiver frustration was often high and coupled with anger, emotional strain, resentment, and sorrow, although caregivers felt they were obligated to show love, empathy, compassion, and hope. Caregivers came to a gradual recognition that the illness could have a long duration or become permanent, and this produced profound sadness and pervasive grief. Isolation could also occur at this stage. Expectations were revised, particularly among parents who had anticipated success and happiness for their children. Anger, and sometimes hate, were directed at the disease and not the family member. Caregivers often distanced themselves because of the fear of losing themselves and their identities. They then came to acceptance and gave up the need for fixing the disease and being in control. "Letting go" without guilt was the next step in the process and involved new acceptance, admiration, and respect for the family member who was ill and struggling with the unimaginable pain of mental illness.

\section{Conclusions}

Living with a family member who has a mental illness was a complex process involving confusion before and around the time of diagnosis, frustration and optimism as the disease progressed, and grief and sadness about its permanence. Finally, caregivers came to accept that they could not control or fix the disease and were able to withdraw without guilt, gaining a new respect and admiration for the family member who was ill and struggling.

\section{COMMENTARY}

The research by Karp and Tanarugsachock examines the process experienced by relatives of a person diagnosed with a serious mental illness. The results are consistent with other studies that have found predictable stages related to the development of and recovery from mental illness. ${ }^{12}$ The study adds to the literature by illustrating how families go through a similar emotional journey, and adds to the evidence focusing on specific needs of families who have a member diagnosed with a serious mental illness..$^{3-5}$

The sample is largely drawn from a self help group. The findings may therefore be most applicable to family members who tend to actively seek out such supports. Also, the sample includes mostly white, middle class participants. Further research, with more diverse samples, could establish the transferability of the findings.

The identification of phases in the evolution of the caregiving experience has clear practice implications for nurses. The type of support offered to families needs to be congruent with their location along the process trajectory. Nurses may often become involved at the second phase, when a diagnosis is given within the mental health system. Families are described as actively seeking information about the illness at this point, and nurses aware of this need should be prepared to provide the details. A different kind of support is required as the family members perceive the permanence of the illness. Coping strategies, such as balancing involvement and maintaining hope, are necessary to help families through this difficult phase and on to the final phase of acceptance.

Cheryl Forchuk, RN, PhD Associate Professor/ Nurse Scientist University of Western Ontario/ London Health Sciences Centre London, Ontario, Canada

1 Carr VJ. Recovery from schizophrenia: a review of patterns of psychosis. Schizophr Bull 1983;9:95-121.

2 Kotcher M, Smith TE. Three phases of clozapine treatment and phase-specific issues for patients and families. Hosp Community Psychiatry 1993;44:744-7.

3 Dixon L, Lyles A, Scott J, et al. Services to families of adults with schizophrenia: from treatment recommendations to dissemination. Psychiatr Serv 1999;50:233-8.

4 Hatfield AB, Coursey RD, Slaughter J. Family responses to behavior manifestations of mental illness. Innovations Eं Research 1994;3:41-7.

5 Rose LE. Families of psychiatric patients: a critical review and future research directions. Arch Psychiatr Nurs 1996;10:67-76. 